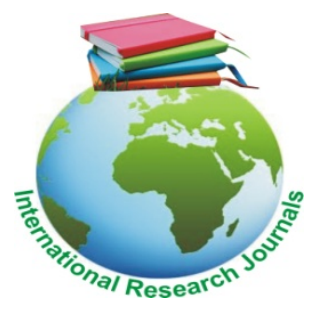

Journal of Medicine and Medical Sciences Vol. 7(3) pp. 056-060, May 2016

Available online http://www.interesjournals.org/JMMS

DOI: http:/dx.doi.org/10.14303/jmms.2016.307

Copyright (C) 2016 International Research Journals

Full Length Research Paper

\title{
Plasma levels of Chromium and Magnesium in Type 2 Diabetes Mellitus and apparently healthy adults
}

\author{
${ }^{1 *}$ Nwegbu Maxwell Madueke, ${ }^{2}$ Egua Maxwell Osaronowen, ${ }^{3}$ Bello Omowunmi Enitan \\ ${ }^{1}$ Department of Chemical Pathology, College of Health Sciences, University of Abuja, Abuja, \\ Nigeria \\ ${ }^{2}$ Department of Pharmacology, College of Health Sciences, University of Abuja, Abuja, Nigeria \\ ${ }^{3}$ College of Health Sciences, University of Abuja \\ ${ }^{*}$ Corresponding Author's E-mail: maxwellnwegbu@gmail.com
}

\begin{abstract}
The study involved the evaluation ofplasma levels of Chromium and Magnesium in diabetic and apparently healthy individuals. This cross sectional study evaluated a total of eighty subjects comprising forty type 2 diabetic patients drawn fromthe University of Abuja Teaching Hospital, and forty apparently healthy individuals from the workforce within the hospital. Anthropometric parameters were measured and blood samples collected from the subjects, who had consented to the study. The glucose indices of the diabetic subjects was estimated by calculating the average fasting plasma glucose in the preceding six months and the subjects grouped into three categories( A (3-7 mmol/dl); B (7-10 mmol/dl); and C (10-14mmol/dl). This glucose index was correlated to the plasma chromium and magnesium levels in the diabetic subjects. Statistical analysis was by IBM SPSS version 21.0. The results showed the mean serum Magnesium(mg/dl) to be $1.48 \pm 0.24$ in diabetic subjects and $1.96 \pm 0.10$ in healthy subjects and the mean serumChromium $(\mu \mathrm{g} / \mathrm{dl})$ to be $0.05 \pm 0.01$ and 0.018 in diabetic and healthy subjects respectively. A positive, though not statisticallysignificant, correlation was noted between the average blood sugar and the serum levels of Chromium and Magnesium in the diabetic subjects.
\end{abstract}

Keywords: Chromium, Magnesium, Diabetes Mellitus andGlucose index.

\section{INTRODUCTION}

Chromium and magnesium belong to the mineral subgroup of micronutrients, which are nutrient substances required in small quantities for normal human physiology encompassinga variety of catalytic, structural and regulatory functions in which they interact with macromolecules in the body (Shenkin, 2005). The importance in health has been indicated in some disease states such as coronary heart disease and other forms of atherosclerotic disease in which, the primary cause is a chronic deficiency of vitamins and other essential nutrients in millions of vascular wall cells that leads to the instability of the vascular walls, lesions and cracks, atherosclerotic deposits and, eventually, heart attacks or strokes (Rath, 2014).

One of such disorders in which chromium and magnesium have been implicated is type 2 diabetes mellitus (T2DM).
T2DM, a group of syndromes characterized by altered metabolism of lipids, carbohydrates, and proteins, and increased risk for cardiovascular disease(CVD), has insulin resistance as its underlying pathophysiologic basis(ADA, 2010).

Deficient states involving these micronutrients have been associated with insulin resistance, poor metabolic control and development of chronic complications in T2DM. (Wang and Cefalu, 2010:Rodriguez-Moran and Guerrero-Romero, 2003). Chromium exists in our environment in several oxidative states, principally as metallic $\left(\mathrm{Cr}^{0}\right)$, trivalent $\left({ }^{+3}\right)$ and hexavalent $\left({ }^{+6}\right)$ chromium (William and Frank, 2004). Of these, the trivalent chromium, found in most foods (meat, egg yolk, green beans, cereals, brewer's yeast, beer and some wine) and nutrient supplements, is an essential nutrient with low toxicity (William and Frank, 2004) and shown to be an 
essential element required for normal carbohydrate and lipid metabolism (Jeejeebhouy et al., 1977). The recommended daily dietary intake for chromium from age 7 years to adulthood is $50-200 \mu \mathrm{g}$ (William and Frank, 2004).

Magnesium, the fourth most abundantcation in the human body and second most abundant intracellular cation (Chetan et al., 2002), is an essential mineral required by the body for maintaining normal muscle and nerve function, keeping a healthy immune system, maintaining heart rhythm, building strong bones and is involved in several biochemical reactions in the body (Phuong-Chi et al.,2007).Evidence has shown a link between hypomagnesemia and dysfunctional insulin receptor function due to reduction in tyrosine-kinase activity which may ultimately result in insulin resistance (Paolisso and Ravussin). It is found in some foods (beans and fish), vegetables (spinach), and fruits(cashew nuts and walnuts) (Fawcett et al., 1999). The recommended daily allowance for magnesium is $6 \mathrm{mg} / \mathrm{kg} /$ day (William and Frank, 2004).

Management of DM involves dietary measures which have been abused mostly by patients in the quest for normal blood sugar levels. It is common for DM patients to refuse or forbid fruits and certain other foods (rich in micronutrients) in the belief of their having high sugar content.

The awareness of the importance of these micronutrients is increasing and is now common-place to observe sectionsin drug-stores, and malls dedicated to several formulations from different drug companies. In this study conducted in the University of Abuja Teaching Hospital(UATH) Gwagwalada, a tertiary level hospital, we compared the patterns of plasma chromium and magnesium levels between T2DM subjects and appaently healthy adult controls.

\section{MATERIALS AND METHODS}

This cross sectional study used a convenient sampling technique to select 40 diabetic patients and 40 apparently healthy individuals. The diabetic subjects were recruited from the endocrinology clinic of UATH while the apparently healthy subjects were from the hospital workforce.The diabetic subjects were patients who were relatively stable and not in any form of clinically discernible acute complications. Subjects were informed of the purpose of the study and afterwards informed consent was obtained from willing participants. Ethical approval was gotten from the UATH Health Research Ethics Committee.

\section{Procedure}

Socio demographic and nutritional data of the study subjects were obtained using a questionnaire. Anthropometric parameters viz weight, height and body mass index were measured and documented. The subjects had asepticvenipuncture and blood specimens collected in a K2-EDTA-vacutainer. Theblood samples were centrifuged at 5000rpm, and the plasma transferred to empty sterile glass tube containers. One millimeter of each plasma specimen was deproteinized with $9 \mathrm{ml}$ of $10 \%(\mathrm{w} / \mathrm{v})$ trichloroacetic acid in $0.11 \%$ of lanthanum solution for microelement analysis. The supernatant was diluted with $0.11 \%$ of lanthanium and aspirated to the atomic absorption spectrophotometer (AAS) (Buck Scientific 205AAS ${ }^{\mathrm{TM}}$ ).

Determination of chromium and magnesium; Two separate standard and blank solutions were prepared by diluting plasma with $5 \%$ glycerine, while each test plasma sample was constituted by a 1:4 dilution with distilled and deionized water. These were subsequently read at wavelengths of $357.9 \mathrm{~nm}$ and $285.2 \mathrm{in}$ the AAS, for chromium and magnesium respectively.

\section{Calculation}

The concentrations of the elements were calculated using the formula:

$M g / l=p p m=R x D$

And $\mathrm{R}=\mathrm{AAS}$ reading

$D=$ diluting factor

Ppm=parts per million

The glucose indices of the diabetic subjects (specifically defined in this study) as the mean fasting blood glucose over the last 3 visits to the hospital in the last six months, was estimated and values classified into 3 categories: A. 3-7 mmol/dl; B. 7-10 mmol/dl; and C. 10$14 \mathrm{mmol} / \mathrm{dl}$.

\section{Data analysis}

The data analysis of the study findings was by BMI SPSS statistics version 21.0. The plasma level of chromium and magnesium were correlated with the average fasting plasma using the Pearson correlation coefficient with significance at $p \leq 0.10$, while comparison of means was done with student $t$-test with the level of significance set at $\mathrm{p} \leq 0.05$.

\section{RESULTS}

Of the 40 diabetic subjects, males and females were equally distributed. The bulk of the diabetic subjects were civil servants and retirees $(55 \%)$, while amongst the apparently healthy /control group, $75 \%$ of who were from the hospital administrative section, one-third were females and the rest males. Ten percent and $12.5 \%$ of the diabetic and control groups were moderate alcohol 
Table 1: Mean plasma chromium and magnesium levels

\begin{tabular}{lcccc}
\hline $\begin{array}{l}\text { Subjects } \\
\mathbf{n = 4 0}\end{array}$ & Age & BMI $\left(\mathrm{Kg} / \mathrm{m}^{2}\right)$ & $\begin{array}{c}\text { Serum } \\
\text { Magnesium(mg/dl) }\end{array}$ & $\begin{array}{c}\text { Serum } \\
\text { Chromium }(\boldsymbol{\mu g} / \mathrm{dl})\end{array}$ \\
\hline Diabetic & $54.15 \pm 10.93$ & $24.88 \pm 5.32$ & $1.48^{*} \pm 0.24$ & $0.05^{*} \pm 0.01$ \\
Control & $36.75 \pm 9.63$ & $25.39 \pm 4.64$ & $1.96^{*} \pm 0.10$ & $0.018^{*} \pm 0.00$ \\
\hline
\end{tabular}

$*=p<0.05$

drinkers, while $2.5 \%$ of the diabetics smoked as against none in the health subject group. A sizeable number of the subjects in both groups (diabetic- 62.5\%: control$85 \%$ ) subscribed to daily intake of vegetables.

Among the diabetic subjects, 33 of the 40 subjects were on oral antidiabetic therapy while 7 were on herbal drugs. One of the diabetic subjects was on antacids while $17.5 \%$ of them were on nutritional supplements. Use of supplements and herbal drugswas noted in $20 \%$ and $5 \%$ of the healthy controls respectively.

While the nutritional supplements were basically mulita-vitamin and mineral combination drugs, the constituents of the herbal drugs could not be ascertained.

\section{Correlation of average fasting blood glucose to chromium and magnesium in diabetic subjects}

The Pearson Correlation coefficient between average fasting blood glucose and chromium in diabetic subjects was negative $(-0.088)$ but not significant $(p=0.619)$. In contrast, the Pearson Correlation coefficient between average fasting blood glucose and magnesium in diabetic subjects was positive (0.259) but not statistically $(p=0.139)$.

\section{DISCUSSION}

Trace elements or micronutrients have been shown to regulate hormone secretion/function (Henkin, 1976), play an important role in the pathophysiology of certain disease states (Rath, 2014) and is usually affected in the course of disease (Brown et al., 1986). In this study carried out to compare the plasma levels of chromium and magnesium in diabetics and apparently healthy subjects, the mean Serum Chromium $(\mu \mathrm{g} / \mathrm{dl})$ in diabetic subjects $(0.05 \pm 0.01)$ was significantly $(p<0.05)$ higher than that in the healthy subjects( $0.018 \pm 0.00$.). This higher level of chromium in diabetic subjects has also been documented in other studies such as Aharoniet al., 1992, who worked with pregnant diabetic women and also in a study by Zima et al., 1998. These findings are in contrast to some other studies, as the disease state and pregnancy have been adduced as factors that deplete body chromium; it has been stated that diabetic subjects have an increase renal excretion of chromium (Jeejeebhoy et al., 1977).

However, it has also been documented that there exists compensatory increase in the intestinal absorptionof chromium in diabetes (Jeejeebhoy et al., 1977 ) and coupled with the use of dietary supplementation as was reported in this study (17.5\%), could account for the higher plasma levels of chromium amongst the diabetics than that of the healthy subjects.Although it may be difficult to explicitlyexplain the basis of the findings of studies such as ours, the fact of the central role of chromium in enhancing insulin binding and signaling, modulation of insulin receptor number and overall enhances $\beta$-cell sensitivity is not in doubt(Hua et al., 2012).

However it is important to state that factors such as the analytical tools employed to assess blood levels of chromium, the influence of antidiabetic drugs to which the subjects were already on and the fact that these clinical studies were conducted in subjects with full-blown diabetes and not in pre-diabetic patients have been suggested as the basis for divergent findings in many studies(Hua, 2012). It is likely that chromium may be augmenting insulin actions in pre-diabetic patients (Hua, 2012). An incidental findings in our study was that the apparently healthy subject group had a slightly higher mean BMI than the diabetic group (25.4 vs $\left.24.9 \mathrm{~kg} / \mathrm{m}^{2}\right)$. Could this have been an influence on the outcomes of the mean plasma chromium levels between the two groups given the association of obesity and insulin resistance? However it is also important to note that there have been findings that did not establish any association of low plasma chromium with obesity (Yerlikaya et al, 2013).

The level of plasma magnesium (mg/dl) was significantly lower in the diabetic subjects than the healthy subjects (Table 1 ). This finding had also been reported by Issa et al., 2011, as well as Vincent, 2000 and Zaegar et al., 1998. Hypomagnesemia could have been accounted for by the renal wastage (excessive excretion) seen in diabetes (Phuong- Chi et al., 2007) or part of the course of the disease state since magnesium is a trace element reportedly involved in glucose homeostasis (Resnick et al., 1993). It is also important to note that magnesium deficiency has been associated with insulin resistance (Huerta et al, 2005). It is also important to note that aside analytical methodology, 
Table 2: Plasma chromium levels versus glucose index (diabetic group)

\begin{tabular}{lccc}
\hline Group & Total chromium( $\mu \mathrm{g} / \mathrm{dl})$ & $\begin{array}{c}\text { Mean } \\
\text { chromium }(\mu \mathrm{g} / \mathrm{dl})\end{array}$ & $\begin{array}{c}\text { Standard deviation } \\
\pm\end{array}$ \\
\hline $\begin{array}{l}\mathrm{A} \\
(3-7 \mathrm{mmol} / \mathrm{dl})=15.0\end{array}$ & 0.7450 & 0.0497 & 0.0082 \\
$\mathrm{~B}$ & & & \\
$(7-10 \mathrm{mmol} / \mathrm{dl})=13.0$ & 0.6380 & 0.0491 & 0.0054 \\
$\mathrm{C}$ & & & 0.0078 \\
$(10-14 \mathrm{mmol} / \mathrm{dl})=12.0$ & 0.5890 & 0.0491 & \\
\hline
\end{tabular}

On comparing the means using t-test, there was no significant difference in the groups as $p>0.05$

Table 3: Plasma magnesium levels versus glucose index (diabetic group)

\begin{tabular}{lccc}
\hline Group & Total magnesium(mg/dl) & Mean magnesium(mg/dl) & Standard deviation \pm \\
\hline A & 21.5380 & 1.4359 & 0.2576 \\
$(3-7 \mathrm{mmol} / \mathrm{dl})=15.0$ & 18.9690 & 1.4592 & 0.2407 \\
B & & & 0.2036 \\
$(7-10 \mathrm{mmol} / \mathrm{dl})=13.0$ & 18.6060 & 1.5505 & \\
C & & & \\
$(10-14 \mathrm{mmol} / \mathrm{dl})=12.0$ & & & \\
\hline
\end{tabular}

On comparing the means using t-test, there was no significant difference in the groups as $p>0.05$

factors such as race, lifestyle and geographical influence have also been shown to influence outcomes of findings involving chromium (Yerlikaya et al, 2013).

In the correlation of the glucose indices of the diabetic subjects to the levels of serum chromium and magnesium, there was a negative correlation but insignificant relationship between plasma chromium level and glucose index. The finding was opposite for magnesium, in that there was positive correlationbut similarly without statistical significance. The strength of association for both micronutrients vis a vis glucose index was weak for both parameters.Another important finding in our study was the fact that a number of our subjects were on herbal medications whose constituents could not be ascertained. This highlights the need for physicians to ensure that information such as this is gotten from their patients as they may impact therapeutic outcomes.

In conclusion, our study findings show that plasma levels of magnesium were lower in diabetic subjects compared to apparently healthy controls in contradistinction to plasma chromium levels. We also observed that glycaemic control may not have much effect on the plasma levels of these micronutrients as had been reported by Ekmecioglu et al., 2001.

\section{ACKNOWLEGEMENT}

The authors will like to acknowledge the assistance of the technical staff of the International Institute of Tropical Agriculture (IITA) Ibadan in the analysis of the samples.

\section{REFERENCES}

AharoniA, Betsalel T, Paltieli Y (1992). Hair chromium content of women with gestational diabetes compared with non diabetic pregnant women. Am J ClinNutr. 55:104-7.

American Diabetes Association [ADA] (2010). Diagnosis and Classification of Diabetes Mellitus. Diabetes Care.33 (1) ;S62- S69.

Brown RO, Forloines Lynn S, Cross R.E, Heizer WD (1986). Chromium deficiency after long parenteral nutrition.Dig Dis Sci. 31661-664.

Chetan PH, Sialy R, Devi DB (2002).Magnesium deficiency and diabetes mellitus. Current sci.83;12- 15.

Ekmecioglu C, Prohaska K, Stefan I, Mark W (2001). Concentration of seven trace element in different haematological matrices in patients with type 2 diasbetes as compared to healthy controls. BiolTra. Elem. 79(3): 205-19.

Fawcett WJ, Haxby EJ, Male DA (1999).J Anaesth.83; 302-320.

Henkin R.I. (1976). Trace metal in endocrinology. Med. Clin North Am.60; 779-97.

Hua Y, Clark S, Ren J, Sreejayan N (2012). Molecular mechanisms of Chromium in alleviating insulin resistance.J Nutr.Biochem. 23(4): 313-319.

Huerta MG, Roemmich JN, Kington ML, Boybjerg VE, Weltman AL, Holmes VF, Patrie JT, Rogol AD, Nadler JL (2005). Magnesium Deficiency Is Associated With Insulin Resistance in Obese Children. Diabetes Care.28(5): 1175-1181.

IssaN, Ismail KS, Mohammad S, Ladan G, Hoossein N (2011). Zinc, Copper, Chromium, Manganese and Magnesium levels in serum and hair of insulin dependent diabetics. Archives of Iranian Med. (AIM).

Jeejeebhouy KN, Chu RC, Marliss EB, Greenberg GR, BruceRobertson A (1977).chromium deficiency, glucose intolerance, and 
nueropathy reversed by chromium suplimentation in a patient receiving total parenteral nutrition. Am J ClinNutr. 30: 531-538.

Paolisso G, Ravussin E (1995).Intracellular magnesium and insulin resistance: results in Pima Indians and Caucasians.J ClinEndocrinolMetab.80:1382-1385.

Phuong- Chi TP, Phuong- Mai T.Son V, Jeffrey MM, Phuong- Thu T (2007). Hypomagnesium in patients with type 2 diabetes.CJASN.2; 366-373.

Rath M (2014). Vitamins and Other Nutrients Can Halt and Reverse Coronary Heart Disease.Dr.RathHealthFoundation.http://www4. drrathfoundation.org/NHC/cardiovascular_disease/cellular_solutions .htm

Resnick I, Altura BT, Gupta RK, Laragh JH, Alderman MH, Atura BM (1993). Intracellular and extracellular magnesium depletion in type 2 (non -insulin dependent) diabetes mellitus.Diabetologia. 36: 767770 .

Rodriguez-Moran M, Guerrero-Romero F (2003). Oral magnesium supplementation improves insulin sensitivity and metabolic control in type 2 diabetic subjects. Diabetes Care. 26(4): 1147-1152
Shenkin A (2006). The key role of micronutrients.Clinical Nutr.25(1); 1 13.

Vincent JB (2000). The biochemistry of chromium.JNutr.130: 715-718.

Wang ZQ, Cefalu WT (2010). Current concepts about chromium supplementation in type 2 diabetes and insulin resistance. CurrDiab Rep.10:145-51

William TC, Frank BH (2004). Role of chromium in human health and in diabetes.Diabetes care.27(11); 2741-2751.

Yerlikaya F. H., Toker A., Airbas A.(2013). Serum trace elements in obese women with or without diabetes.Indian J Med Res. 137(2): 339-345.

Zaegar AH, Shah NA, Masoodi SR (1998). Copper, Zinc and Magnesium levels in non insulin dependent diabetes mellitus.Post Graduate Med J. 74:665-8.

Zima T, Mestek O, Tesar V, Tesarova P, Nemecek K, Zak A, Zeman M (1998). Chromium levels in patients with internal disease. Biochem. Mol. Int. 46: 365-374. 